\title{
Effectiveness of drainage grooves in road wearing course
}

\author{
M. Moravec \\ Ph.D. student of University Pardubice, Jan Perner Faculty of Transport, Dept. of Transport Infrastructure, \\ Pardubice, Czech Republic
}

K. Pospíšil ${ }^{*}$

CDV - Transport Research Centre, Brno, Czech Republic

*Corresponding author: karel.pospisil@cdv.cz

\begin{abstract}
Surface drainage of road pavements with both a very low longitudinal and transversal gradient is a subject for special solutions. Drainage grooves rabbeted into the road pavement wearing course are one of them. While the costs of this kind of maintenance are not inconsiderable, the effectiveness of such a solution has not yet been independently evaluated. This paper describes experiments done in the field of assessment of the drainage grooves effectiveness.
\end{abstract}

KEY WORDS: Surface drainage, drainage groove, pavement, wearing course

\section{INTRODUCTION}

Occasionally landscape topography or technical reasons cause very low gradient of a road's vertical alignment. This causes a problem with the surface drainage of the road pavement. This situation is solved by additional measures. Pavement surface grooving is one of these. Grooves are made using slotting cutter typically over the whole width of roadway. Usually grooves create drainage lines consisting of several parallel grooves. The drain lines are repeated several times to maintain the appropriate surface drainage of road pavement surface. Figure 1 shows a typical application of grooved drain lines on a cement concrete motorway pavement.

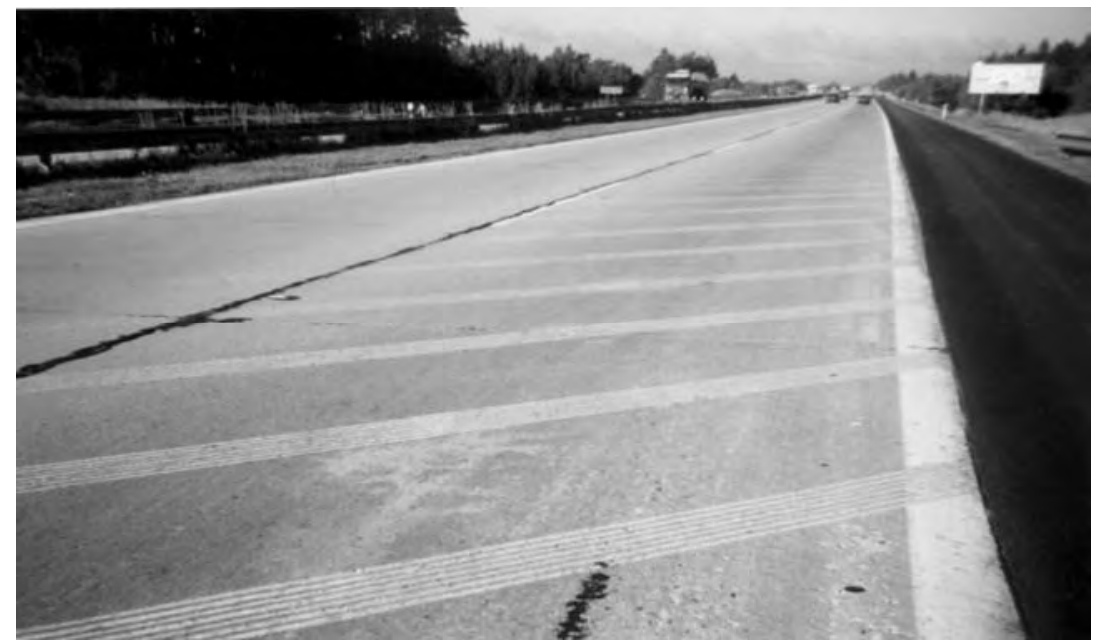

Figure 1: Grooved drain lines on a concrete motorway pavement surface 
The depth of grooves is between 1 and $8 \mathrm{~mm}$, the width typically $30 \mathrm{~mm}$, and the distance between neighboring grooves is from 10 to $200 \mathrm{~mm}$. Schematically, the grooves and drainage line are displayed in Figure 2. Distances between neighboring drainage lines vary greatly and depend on the specific design. An angle formed with the road axis and the direction of a drainage line is usually approximately $\pm 45^{\circ}$.

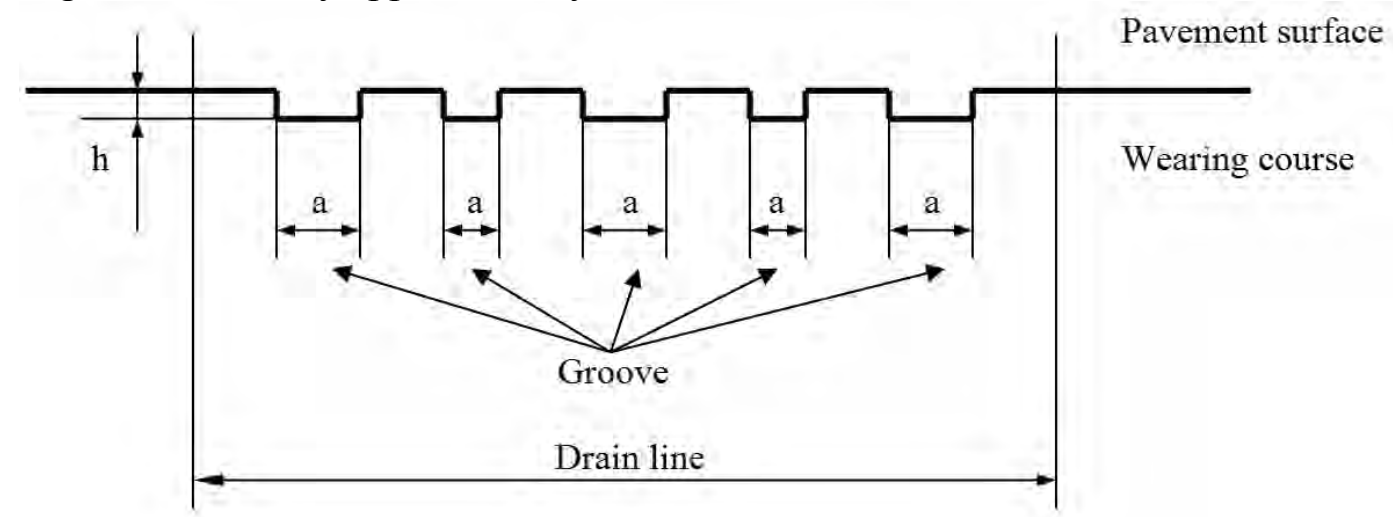

Figure 2: Schematic illustration of grooves constituting a drain line

\section{THEORETICAL BACKGOUND}

Companies offering grooves as an element of the surface drainage system suppose that they can facilitate a water flow in the case of a pavement surface with a gradient of close to zero. Sufficient theoretical analysis of the asset has not yet been presented. It can be taken that a pavement surface with a zero gradient has no capability to drain rainwater. An effective drainage system can permit a laminar water flow which can be attained by the appropriate dimensions of the drain pipe, gutter or groove. Laminar or turbulent water flow can be distinguished by using the critical value of the Reynolds number, which for pipes is 2,320 and for gutters 520 (Veselý, 1985).

Calculation of the Reynolds number in shown in eq. (1).

$$
\operatorname{Re}=\frac{V \cdot R}{v},
$$

where:

$R e$ is the Reynolds number,

$V \quad$ the water flow velocity $\left(\mathrm{m} . \mathrm{s}^{-1}\right)$,

$R \quad$ in the case of pipes: the pipe diameter (m)

in the case of gutters: the hydraulic radius (m), see eq. (2), and

$v \quad$ is the kinematic viscosity $\left(\mathrm{m}^{2} \cdot \mathrm{s}^{-1}\right)$.

The hydraulic radius determination is shown in eq. (2).

$$
R=\frac{S}{C},
$$

where:

$R$ is the hydraulic radius (m),

$S$ the area of cross-section $\left(\mathrm{m}^{2}\right)$, and

$C$ the length of dabbled circumference (m). 
In the case of grooves with a rectangular cross-section the hydraulic radius $\mathrm{R}$ can be expressed using eq. (2) with the dimensions shown in Figure 2: $\mathrm{R}=\mathrm{a} \cdot \mathrm{h} /(2 \mathrm{~h}+\mathrm{a})$. After this modification the equation (1) obtains the form of the equation (3).

$$
\operatorname{Re}_{k}=580 \leq \operatorname{Re}=\frac{V \cdot a \cdot h}{v \cdot(2 h+a)},
$$

where:

$R e_{k}$ is the critical value of Reynolds number for open gutters is 580 (Veselý, 1985),

$R e, V$ have the same expression as in eq. (1),

$v \quad$ is the kinematic viscosity $\left(\mathrm{m}^{2} . \mathrm{s}^{-1}\right)$; water kinetic viscosity in $20^{\circ} \mathrm{C}$ is $1.01 .10^{-6} \mathrm{~m}^{2} . \mathrm{s}^{-1}$,

$h \quad$ the depth of groove (m), and

$a$ the width of groove $(\mathrm{m})$.

The equation (3) shows that the value of the Reynolds number can be influenced by the preference of the relation between the depth and width of the gutter. In the case of grooves there are technological limitations - the width cannot be expanded due to fluent wheel crossing and the deepening of the grooves may cause structural problems of the pavement wearing course.

Water can be taken as an incompressible liquid of constant mass density (in the case of this particular experiment) and its flow in an isolated system can be expressed by the Bernoulli equation (4) - taken from Wikipedia.

$$
\frac{V^{2}}{2}+g z+\frac{p}{\rho}=\text { const. }
$$

where:

$V$ is the fluid flow velocity at a point on a streamline $\left(\mathrm{m} . \mathrm{s}^{-1}\right)$,

$g \quad$ the acceleration due to gravity $\left(\mathrm{m} . \mathrm{s}^{-2}\right)$,

$z \quad$ the elevation of the point above a reference plane $(\mathrm{m})$,

$p \quad$ the pressure at the point $(\mathrm{Pa})$, and

$\rho \quad$ the density of the fluid at all points in the fluid $\left(\mathrm{kg} \cdot \mathrm{m}^{-3}\right)$.

The Bernoulli equation (4) expresses the law of 'conservation of energy' which states that the total amount of energy in an isolated system remains constant. This means that in an isolated system the increase of flow speed causes a decrease in pressure. In the case of water in the groove, which is not crossed by any wheel, the total amount of energy can be taken as zero (no flow, no pressure, no elevation - reference plane can be placed to the groove bottom). It can be expressed in the equation (5), which is an analogy of equation (4), taking in to account const. $=0$.

$$
\frac{V^{2}}{2}+g z=\frac{p}{\rho} \quad \text { or } \quad \frac{\rho V^{2}}{2}+g \rho z=p \quad \text { or } \quad V=\sqrt{2 .\left(\frac{p}{\rho}+g z\right)}
$$

Equation (5) in its last form can be modified in eq. (6) to express the current speed, which is increased by additional external pressure $\underline{\Delta p}$ (in this case, by a wheel crossing the groove).

$$
V=\sqrt{2 .\left(\frac{p+\Delta p}{\rho}+g z\right)}
$$


If $\underline{n}$ wheel crossings are considered, the equation (6) can be modified in form of equation (7).

$$
V=\sqrt{2 .\left(\frac{\sum_{i=1}^{n} p_{i}}{\rho}+g z\right)}
$$

If the wheel influence on the groove is continuous (e.g., in case of the applicable groove angle in combination with wheel width), and changing the groove gradient, an integral form of equation (7) can be formulated.

$$
V_{k}^{2}=\frac{2}{\rho} \int_{0}^{k} \frac{\partial p}{\partial x} d x+2 g z
$$

Equation (8) documents that the velocity of water flow in the $\underline{k}$ point depends on the pressure of water and the total elevation of groove. There is a statement above that the pressure in water is caused by the wheel crossings of the groove. The relationship between the pressure of water in the groove and the wheel crossings can be expressed by a functional relation (9).

$$
p=f\left(V_{w}, I, p_{w}, \varphi, s_{w}, s_{g}, T\right)
$$

where:

$V_{w}$ is the speed of wheel $\left(\mathrm{m} \cdot \mathrm{s}^{-1}\right)$,

$I$ the intensity of traffic $=$ number of wheels crossing the groove per time unit (e.g. Hz),

$p_{w} \quad$ the pressure in wheel/tire $(\mathrm{Pa})$,

$\varphi \quad$ the angle between road axis and the groove $\left[{ }^{\circ}\right]$,

$s_{w} \quad$ the shape characteristics of wheel/tire,

$s_{g} \quad$ the shape characteristics of groove, and

$T$ the temperature $\left({ }^{\circ} \mathrm{C}\right)$.

The functional expression (9) of pressure $\underline{p}$ basically depends on pressure of tires $\underline{p}_{\underline{w}}$, speed of tire (vehicle) $\underline{V}_{w}$, the tire-tread pattern $\underline{s}_{w}$ and quality of groove $\underline{s}_{g}$. While the pressure and speed of the tire can be ascertained exactly, the influence of the tire-tread pattern and its interaction with the shape and condition of the groove is a multi-parametric system which could be studied using a stochastic-empirical approach. There are only several parameters of both "shape" characteristics $\underline{s}_{w}$ and $\underline{s}_{g}$, such as depth and width of tire-tread pattern and groove, which can be measurable directly, but there are many others which can be taken quantitatively only by their evidence. A current significant statistical survey on pressure of tires $\underline{p}_{\underline{w}}$ and the thickness of the tire profile is submitted for publication by Moravec, 2008.

There is a special problem with the loss of water flow velocity, expressed by pressure loss in (10), according to Weisbach (e.g. in Allen \& Ditsworth, 1972).

$$
p_{L}=\xi \frac{V^{2}}{2 \rho} \quad \text { or } \quad p_{L}=\lambda \frac{L}{4 \cdot R} \cdot \frac{V^{2}}{2 \rho}
$$

where:

$p_{L}$ is the pressure loss $(\mathrm{Pa})$,

$\xi \quad$ the loss parameter, which is: $\xi=\lambda \frac{L}{4 . R}$, 
$\lambda \quad$ the friction loss parameter,

$L \quad$ the length of searched section (length of groove up to a selected point) (m),

$V, R$ have the same expression as in eq. (1).

Unfortunately more-or-less all parameters of eq. (10) differ groove-to-groove and point of a groove to another point of the same groove, because of uneven wear, inherent dirtiness, local damage, etc.

Analysis of the above mentioned equations and their parameters show that the description of the interaction of a wheel (tire) and the grooved pavement has many uncertain parameters which can significantly influence the effectiveness of grooves, and their drainage lines, as an element of a surface pavement drainage system.

The theoretical analysis also shows that a possible evaluation of the drainage lines functionality can be expressed by a comparison of the water velocity in the case of plain and grooved pavement in dependence on vehicle speed. Therefore, the tests described in the next chapter are targeted to the direct measurement of water velocity on both plain and grooved pavement linked to passing car speed.

\section{TESTS ARRANGEMENT}

\subsection{SELECTION OF LOCALITIES}

The tests were done in two selected localities. The first one had been selected to be on a rural section of the highway I/34 between the villages Michalovice a Šmolovy, as a representative of long-term exploited treatments. Figure 3 documents the state of the drainage lines.
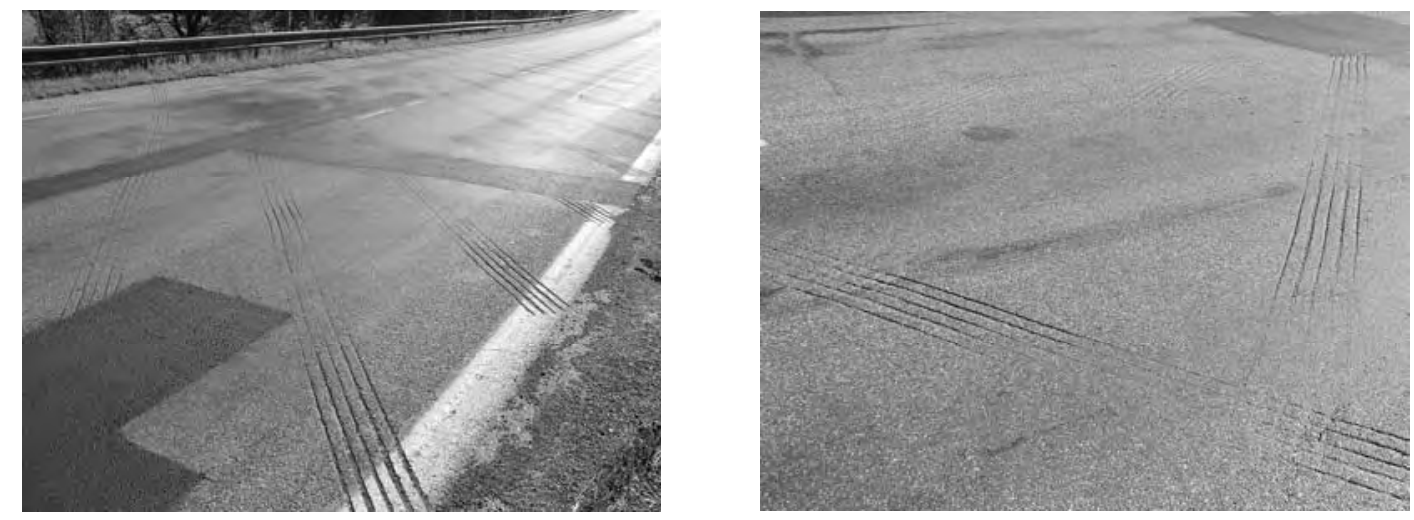

Figure 3: Grooved drainage lines on I/34 highway, exploited and deteriorated treatment

The left picture in Figure 3 shows a general view of the drainage lines' arrangement and the right picture in the figure documents the deterioration of the drainage lines caused by traffic loading.

The second locality of interest is a rural section of the highway I/35 between the village Hřebeč and town Moravská Třebová. This locality is representative of the recently established treatments. Figure 4 displays the status of the treatment at this locality.

Table 1 consists of the measurable parameters for both localities. 
Tab. 1: Parameters of grooves and drainage lines in both of selected localities

\begin{tabular}{|c|c|c|}
\hline Parameter & $\mathrm{I} / 34$ & $\mathrm{I} / 35$ \\
\hline Groove width/depth/distance between drainage lines (mm) & $30 / 4 / 1,300$ & $30 / 5 / 1,100$ \\
\hline Grooves in drainage line/angle in between dr. line and road axis & $5 / 40^{\circ}$ & $5 / 45^{\circ}$ \\
\hline Age of treatment & 10 years & 20 months \\
\hline
\end{tabular}
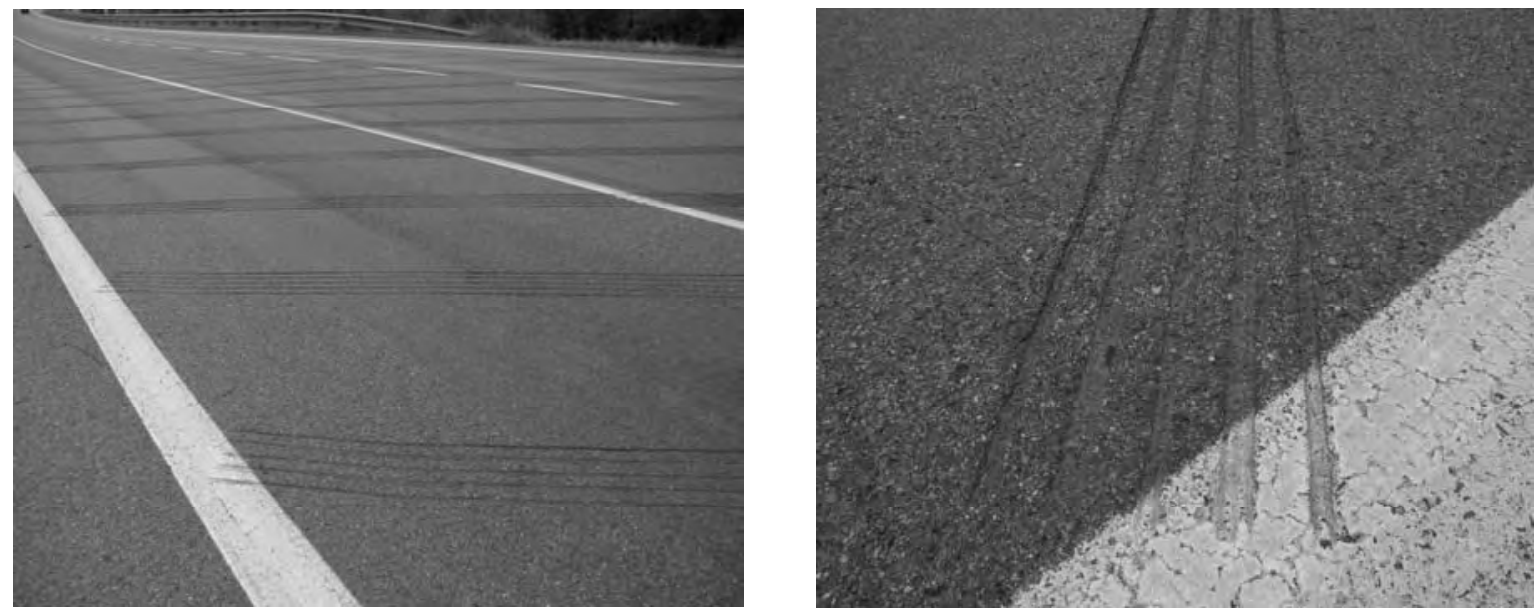

Figure 4: Grooved drainage lines on the I/35 highway, recently established treatment

\subsection{TEST PARAMETERS}

Measurement of the water velocity was carried out using two inductive sensors. One of them was placed in the groove and the second one on the plain pavement. The distance between both sensors was determined at $1.8 \mathrm{~m}$.

The transversal position of the sensors was set up at the closest position to the right wheel path. This sensor's placement minimized the pressure losses described in equation (10).

Experiments were carried out on wet pavement (after rain), and additional water needed for the tests was supplied by a tanker. The speed of vehicles was taken using a radar device and the levels of water on pavement and grooves were controlled using a plastic pattern glued on the pavement surface and the groove bottom.

The number of measured vehicles was determined employing statistical methods taking in to account the estimated dispersion of the statistical set. The number had been set at 300 vehicles in each particular measurement.

All equipment was hidden from car drivers to prevent changes to their behavior due to the tests. For the same reason the tests were arranged for just after rain, when the pavement was "naturally" wet and added water did not cause any unnatural reaction of passing drivers.

\section{TEST RESULTS}

\subsection{TESTS ON I/34 - DETERIORATED TREATMENT}

Tests on the I/34 highway, where the drainage lines were established ten years ago, were done over two summer days in both directions. Results of experiment are summarized in the graphs shown in Figure 5, and parameters which influenced the tests are shown in Table 2. 
The graphs establish a relationship between velocity of drain water and velocity of passing vehicles. As described in the previous chapter, water velocities in the grooves and on plain pavement were collected.

The test results document that there is no significant impact of drainage lines usage in the observed road section. The reason for this finding can be explain by the deterioration of the grooves and their drainage lines.

Visual observation resulted in place of tests shows that deteriorated grooves in connection with local surface defects worsen the drainage functionality of plain pavement.

Tab. 2: Parameters of tests at I/34 highway

\begin{tabular}{|l|c|c|c|c|}
\hline \multirow{2}{*}{} & \multicolumn{2}{|c|}{ from Michalovice } & \multicolumn{2}{c|}{ to Michalovice } \\
\cline { 2 - 5 } & on $4 / 7 / 2008$ & on $7 / 7 / 2008$ & on $4 / 7 / 2008$ & on $7 / 7 / 2008$ \\
\hline Number of vehicles per hour & 257 & 265 & 243 & 240 \\
\hline Av. vehicles velocity $\left(\mathrm{km}^{-1} \mathrm{~h}^{-1}\right)$ & 64.0 & 73.1 & 70.3 & 75.7 \\
\hline Number of measured vehicles & 300 & 300 & 300 & 300 \\
\hline $\begin{array}{l}\text { Longitudinal/ } \\
\text { transversal gradient }\end{array}$ & \multicolumn{2}{|c|}{$-0.8 \% / 0.0 \%$} & \multicolumn{2}{c|}{$0.8 \% / 0.0 \%$} \\
\hline $\begin{array}{l}\text { Average Daily Traffic } \\
\text { (vehicles/24 h -both directions) }\end{array}$ & \multicolumn{3}{|c|}{7,736 (source: RSD, 2005) } \\
\hline
\end{tabular}
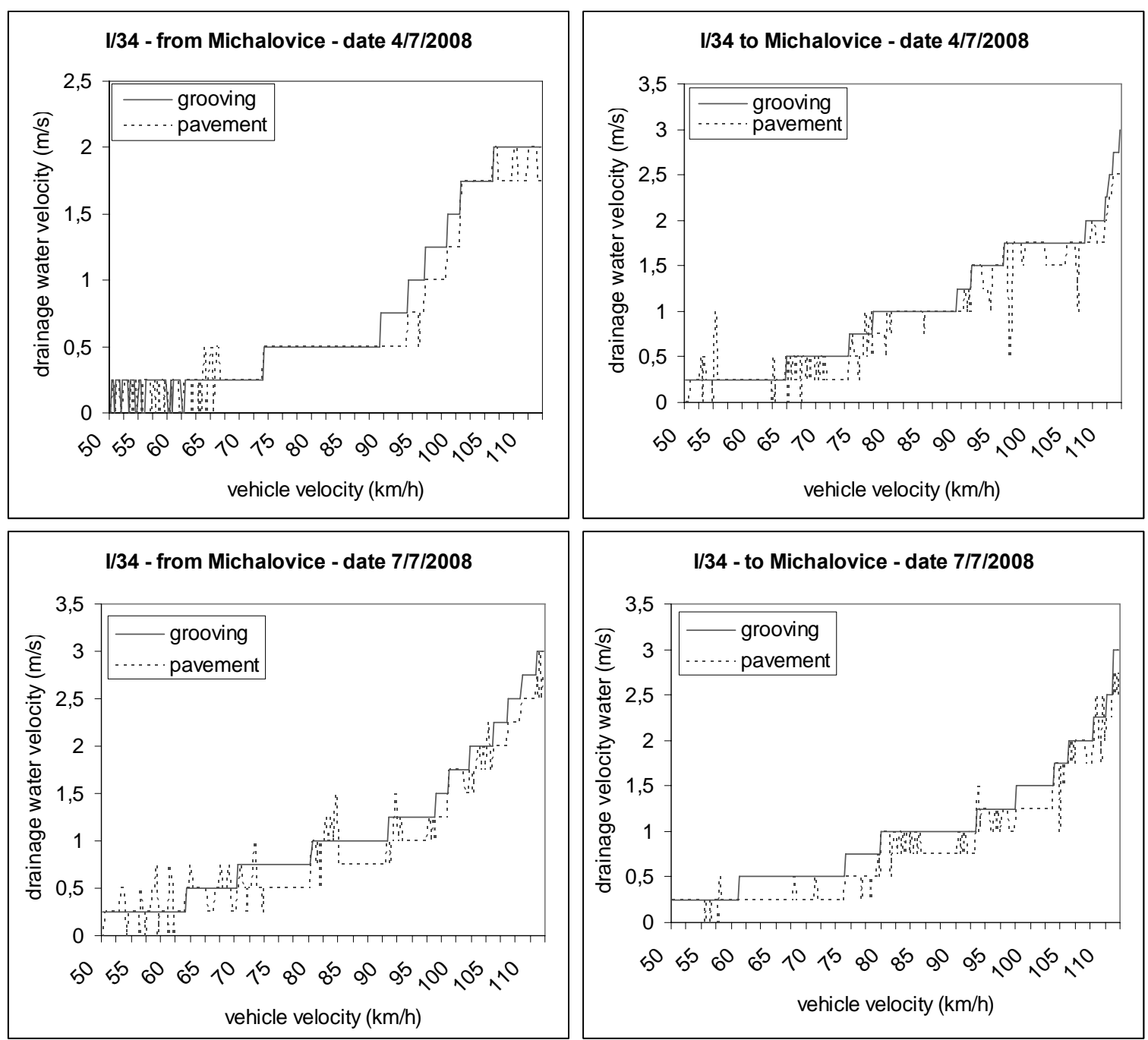

Figure 5: Relationship between drainage water velocity and vehicle velocity on I/34 highway 


\subsection{TESTS ON I/35 - RECENTLY ESTABLISHED TREATMENT}

Tests on the I/35 highway, where the drainage lines were established twenty months ago, were done over three days in both directions. The test arrangement was the same as in the case of $I / 34$. Results of the experiment are summarized in the graphs shown in Figure 6 and input parameters in Table 3. Analogously, as in previously described case, the graphs display a relationship between the velocities of both pavement and groove water drainage and the velocity of passing vehicles.

The test results document that there is only an inconsiderable impact of drainage lines usage in the observed road section. The difference between the velocity of water drainage on plain pavement and the velocity of water in the groove, shown in the majority of Figure 6 graphs, is not so high. The small recognizable difference can be expressed through the accuracy of the measurement method. There is an exclusion displayed in the last (sixth) graph of Figure 6.
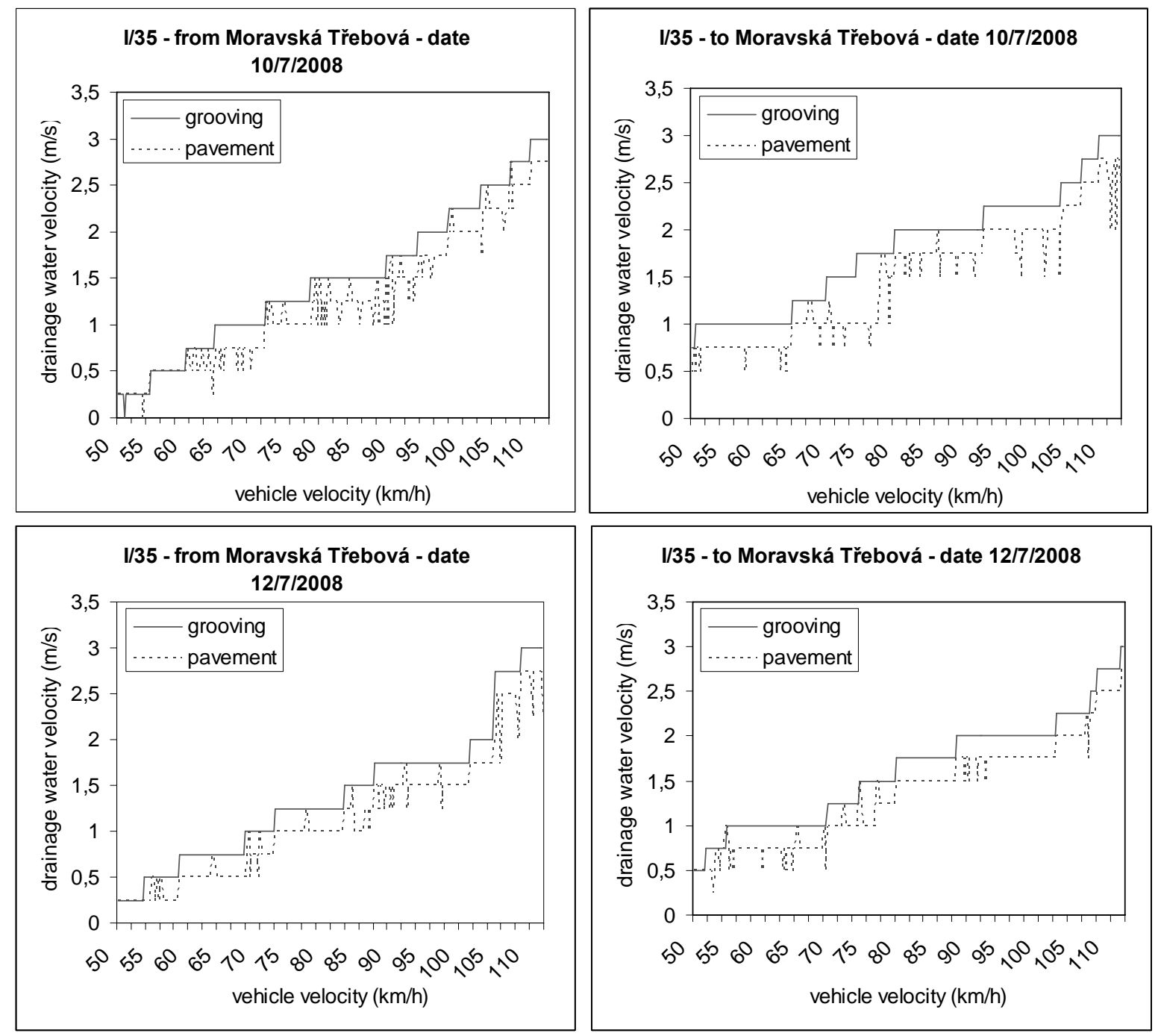

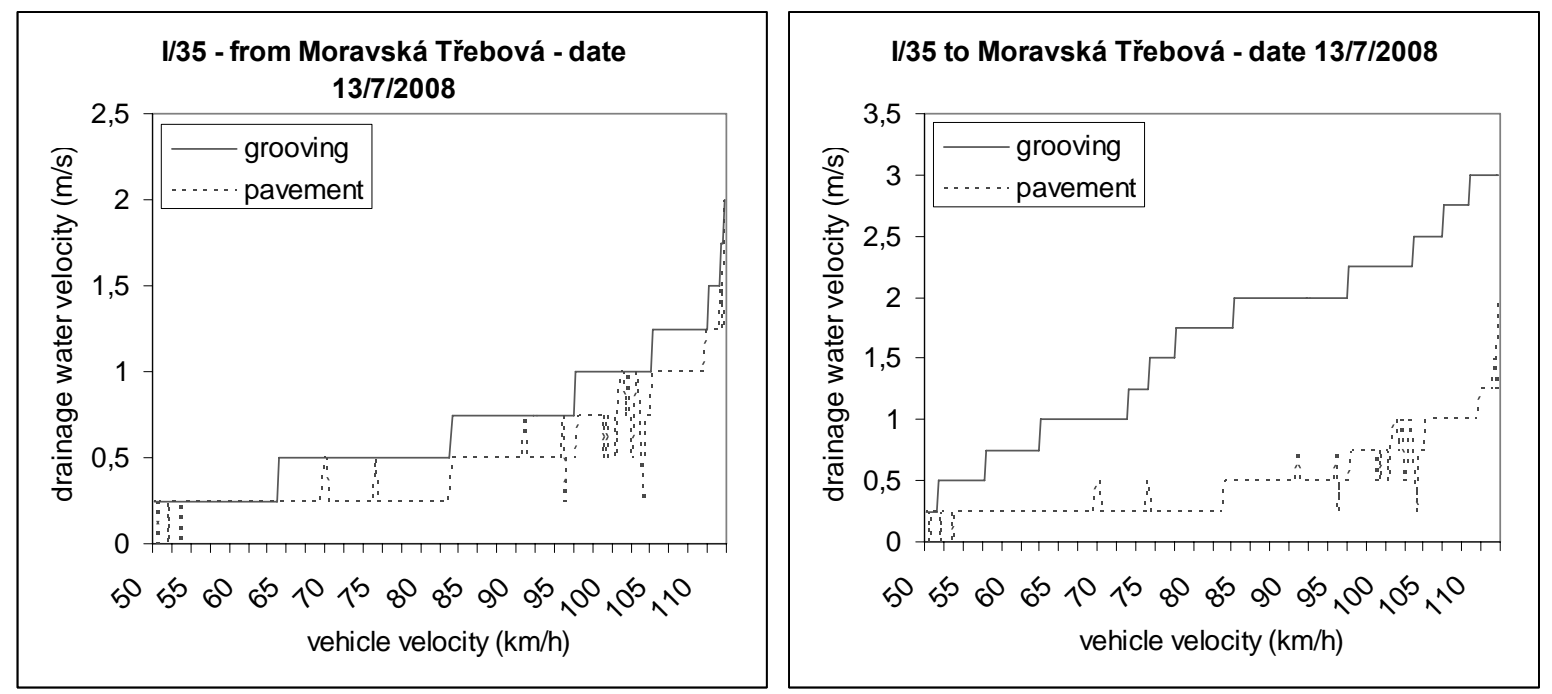

\section{Figure 6: Relationship between drainage water velocity and vehicle velocity on I/35 highway}

The last graph of Figure 6 documents the relatively large difference between the velocity in the groove and the velocity measured on the plain pavement. Looking to Table 3 can give the answer: conformable with the described theoretical base, the pressure in water depends on the intensity of the traffic, see eq. (9). While the traffic intensity in all other cases is approximately 240 vehicles per hour, in the exceptional case described the traffic intensity is 375 vehicles per hour. It seems the main influence on the effectiveness of grooves as an element of the pavement surface drainage system is due to this fact.

Tab. 3: Parameters of tests at I/35 highway

\begin{tabular}{|c|c|c|c|c|c|c|}
\hline & \multicolumn{3}{|c|}{ from Moravská Třebová } & \multicolumn{3}{|c|}{ to Moravská Třebová } \\
\hline & on $10 / 7$ & on $12 / 7$ & on $13 / 7$ & on $10 / 7$ & on $12 / 7$ & on $13 / 7$ \\
\hline Number of vehicles per hour & 243 & 205 & 225 & 217 & 250 & 375 \\
\hline Av. vehicles velocity $\left(\mathrm{km} \cdot \mathrm{h}^{-1}\right)$ & 79.7 & 78.0 & 59.3 & 93.2 & 88.9 & 84.7 \\
\hline Number of measured vehicles & 300 & 300 & 300 & 300 & 300 & 300 \\
\hline $\begin{array}{l}\text { Longitudinal/ } \\
\text { transversal gradient }\end{array}$ & \multicolumn{3}{|c|}{$4.5 \% / 0.5 \%$} & \multicolumn{3}{|c|}{$-4.5 \% / 0.5 \%$} \\
\hline $\begin{array}{l}\text { Average Daily Traffic } \\
\text { (vehicles/24 h -both directions) }\end{array}$ & \multicolumn{6}{|c|}{ 13,297 (source: RSD, 2005) } \\
\hline
\end{tabular}

\section{CONCLUSION}

Although the optimal dimensions of grooves can help with achieving a higher value of the Reynolds number, see eq. (3), and a lower pressure loss, see eq. (10), which allows stabile laminar water flow, there are technical and operational limitations. The width of the groove is limited by the ability of the wheel to cross the groove fluently, without an excessive dynamic effect to the vehicle and the environment. The depth of the groove is restricted by the structural integrity of the pavement wearing course and the possibility of its maintenance (cleaning). Both the Reynolds number and the pressure loss, calculated using eq. (3) and (10), are changing during the groove exploitation (abrasion, dirtiness, etc.). It caused instable groove behavior within its operation period. The performed experiments reflect that drainage lines consisting of grooves are not broadly usable as a tool for the surface 
drainage of pavements. Tests done on deteriorated and recently established drainage lines show very similar unconvincing findings.

It was observed that both damaged and undamaged grooves have no impact on the speed of drainage if the traffic intensity is approximately 240 vehicles per hour. At the same time it is necessary to say that a significant influence was found in the case of traffic intensity of 375 vehicles per hour, see Figure 6, last (sixth) graph, and Table 3, last column. In comparison with the Average Daily Traffic 13,297 vehicles per 24 hours in both directions, see Table 3, a measured traffic intensity of 375 per hour is achieved in the majority of the road performance time. Therefore it seems that the drainage lines consisting of the grooves are a convenient solution for these places. If we adopt this finding, the aforementioned final graph in Figure 6 documents that traffic intensity is not the only parameter of regular drainage lines functionality. In conformity with equation (9), the pressure in water flow in the groove depends on the traffic speed as well. It seems that this dependence is not directly proportional because there is no observed difference between the drainage of plain and grooved pavement up to speeds of traffic of $60 \mathrm{~km} \cdot \mathrm{h}^{-1}$. A more verisimilar explanation of the singularly different result of one test from the additional nine tests is in the wrong functionality of sensor collecting water velocity data from the plain surface. This hypothesis is supported by the fact that velocities of water in grooves are more or less the same in all the cases shown in Figure 6, but only the velocity of water on the plain pavement in the last graph of Figure 6 significantly differs from the others.

The performed experiments do not confirm any positive influence of drainage lines consisting of grooves on the surface drainage of pavements. It can be recommended to continue with experiments aiming to the clarification of the influence of particular parameters affecting pressure, i.e., the speed of vehicles, traffic intensity, the pressure in the tire, shape characteristics of the tire and groove, temperature. This research can result in a more elaborated functional dependence than expressed in the wide and general definition of equation (9).

\section{REFERENCES}

Allen, T., Ditsworth, R. L., 1972. Fluid Mechanics, McGraw Hill, New York.

Moravec, M., 2008. Průzkum stavu pneumatik použivaných v ČR [Survey on Tire Status Used in the Czech Republic]. 6/2008. Doprava [In Czech] (submitted).

RSD, 2005. Sčitáni dopravy v roce 2005 [Traffic Counting in the year 2005]. http://www.scitani2005.rsd.cz/html/1_pa.htm. Ředitelství silnic a dálnic ČR [Road and Motorway Administration of the Czech Republic]. [Online].

Veselý, J., 1985. Vodohospodářské inženýrství [Water Management Engineerig]. Brno University of Technology, School of Civil Engineering [In Czech]. 